\title{
Generation and Characterization of Torudokimab (LY3375880): A Monoclonal Antibody That Neutralizes Interleukin-33
}

\author{
Angela J Okragly (D) \\ Katie Brannon Corwin (iD ${ }^{2}$ \\ Marikka Elia iD $^{3}$ \\ Dongmei $\mathrm{He}^{3}$ \\ Oliver Schroeder ${ }^{3}$ \\ Qing Zhang ${ }^{3}$ \\ Tatiyana Shiyanova (iD) ${ }^{2}$ \\ Stuart Bright' \\ Sarah B Dicker ${ }^{4}$ \\ Lukasz Chlewicki ${ }^{4}$ \\ Stephanie ME Truhlar ${ }^{3}$ \\ Julian Davies $(\mathbb{D})^{3}$ \\ Chetan N Patel ${ }^{2}$ \\ Robert J Benschop (D) \\ 'Immunology Research, Eli Lilly and \\ Company, Indianapolis, IN, USA; \\ ${ }^{2}$ BioTechnology Discovery Research, Eli \\ Lilly and Company, Indianapolis, IN, USA; \\ ${ }^{3}$ BioTechnology Discovery Research Eli \\ Lilly and Company, San Diego, CA, USA; \\ ${ }^{4}$ ADME, Eli Lilly and Company, \\ Indianapolis, IN, USA
}

Background: Interleukin-33 (IL-33) is an alarmin that is released following cellular damage, mechanical injury, or necrosis. It is a member of the IL-1 family and binds to a heterodimer receptor consisting of ST2 and IL-1RAP to induce the production of a wide range of cellular mediators, including the type 2 cytokines IL-4, IL-5 and IL-13. This relationship has led to the hypothesis that the IL-33/ST2 pathway is a driver of allergic disease and inhibition of the IL-33 and ST2 association could have therapeutic benefit.

Methods: In this paper, we describe the selection of a phage antibody through the ability to bind human IL-33 and block IL-33/ST2 interaction. This hit antibody was then affinity matured by site-directed mutagenesis of the antibody complementarity-determining regions (CDRs). Further characterization of a fully human monoclonal antibody (mAb), torudokimab (LY3375880) included demonstration of human IL-33 neutralization activity in vitro with an NFאB reporter assay and IL-33 induced mast cell cytokine secretion assay, followed by an in vivo IL-33-induced pharmacodynamic inhibition assay in mice that used IL-5 production as the endpoint.

Results: Torudokimab is highly specific to IL-33 and does not bind any of the other IL-1 family members. Furthermore, torudokimab binds human and cynomolgus monkey IL-33 with higher affinity than the binding affinity of IL-33 to ST2, but does not bind mouse, rat, or rabbit IL-33. Torudokimab's half-life in cynomolgous monkey projects monthly dosing in the clinic.

Conclusion: Due to torudokimab's high affinity, its ability to completely neutralize IL-33 activity in vitro and in vivo, and the observed cynomolgus monkey pharmacokinetic properties, this molecule was selected for clinical development.

Keywords: IL-33, Th2 immune response, monoclonal antibody

\section{Introduction}

IL-33 is a member of the IL- 1 cytokine family that includes IL- $1 \alpha$, IL- $1 \beta$, and IL-18 1 and is constitutively expressed in structural and lining cells including fibroblasts, endothelial, and epithelial cells of skin, gastrointestinal tract, and lungs. ${ }^{2-4}$ Full-length IL-33 contains a chromatin binding domain that results in nuclear localization. ${ }^{5,6} \mathrm{IL}-$ 33 is released in its full-length form after cellular damage, mechanical injury, or necrosis, thus functioning as an alarmin. The full-length IL-33 is cleaved into a mature cytokine form by a variety of proteases. ${ }^{4,7,8}$ The effects of IL-33 are mediated through its interaction with a heterodimeric receptor consisting of membrane-bound ST2 (also known as IL1RL1) and IL-1RAP, leading to NFkB and MAPK activation. ${ }^{9,10}$ Binding of IL-33 to its receptor activates $\mathrm{T}$ cells, ${ }^{1,11}$
Correspondence: Angela J Okragly Immunology Research, Eli Lilly and Company, Lilly Corporate Center, Indianapolis, IN, 46285, USA

Tel + I- 317-276-2839

Email okragly_angela@lilly.com 
basophils, ${ }^{12}$ mast cells, ${ }^{13}$ eosinophils, ${ }^{14}$ type 2 innate lymphoid cells (ILC2), ${ }^{15,16}$ dendritic cells, ${ }^{17}$ endothelial cells and epithelial cells, ${ }^{18}$ causing the production of numerous pro-inflammatory mediators.

IL-33 induces the production of canonical type 2 cytokines, IL-4, IL-5 and IL-13. ${ }^{1,12}$ These type 2 downstream mediators can give rise to many of the hallmarks of allergic response such as increase in IgE production, increase in eosinophil migration into allergic inflammatory tissues, mucus production, airway hyperresponsiveness, etc. that drives disease pathology. ${ }^{19-21}$ Atopic dermatitis is one of the most common chronic inflammatory skin diseases and its pathogenesis includes impaired skin barrier function, excess type 2 cytokine production and severe pruritus. ${ }^{22,23}$ In association studies, genes encoding IL-33 and its receptors have been identified as susceptibility loci in allergic disease. $^{24-30}$ In humans, both IL-33 mRNA and protein are substantially elevated in the inflamed skin lesions of patients with atopic dermatitis when compared with non-inflamed skin. $^{31}$ In addition, IL-33 is a chemoattractant for both $\mathrm{T}$ helper type 2 (Th2) and ILC2, which are enriched in human atopic dermatitis lesions. ${ }^{32,33}$ In mice, skin-specific expression of IL-33 has been shown to activate ILC2 cells, elicit allergic skin inflammation and scratching behavior, ${ }^{34}$ and it has been demonstrated that IL-33/ST2 signaling excites sensory neurons and mediates itch response. ${ }^{35}$ Together, these data suggest that IL-33 could be an important component in the pathogenesis of atopic dermatitis.

Because IL-33 is an alarmin, acts locally at the sites of inflammation and is upstream of the canonical type 2 cytokines, its neutralization may have the potential for efficacy in patients with allergic diseases. Therefore, the development of a neutralizing antibody recognizing human IL-33 was undertaken resulting in torudokimab, which began a first-in-human study in November 2017 (NCT03343587) and a Phase 2 study in atopic dermatitis in February 2019 (NCT03831191) to test the hypothesis that IL-33 neutralization could be of therapeutic use in atopic dermatitis and other allergic diseases. This report describes the generation and characterization of torudokimab (LY3375880), a fully human IL-33-neutralizing antibody.

\section{Materials and Methods}

\section{IL-33, ST2 and Antibody Expression and Purification}

Recombinant IL-33 ligands were expressed and purified from E. coli cells in-house. Human IL-33 (UniProt
\#095760) was expressed as both Thr90-Thr270 and Ala95-Thr270 fragments representing the cleaved mature form of IL-33. Mouse (UniProt \#Q8BVZ5) and rat (UniProt \#Q66H70) IL-33 ligands were generated as Ala102-Ile266 and Ser109-Met264 fragments, respectively. The sequences for cynomolgus monkey and rabbit IL-33 were not available, so the Rapid Amplification of cDNA Ends (RACE) method was used to obtain the coding sequences of cynomolgus monkey IL-33 and rabbit IL33 from cynomolgus monkey brain cDNA and rabbit brain cDNA, respectively. From the resulting clones, recombinant rabbit IL-33 (Ala101-Ser254) and cynomolgus monkey IL-33 (Ala95-Ile270) were also expressed and purified.

Recombinant monomeric human ST2 was produced in-house. First, a mammalian expression plasmid was generated encoding the extracellular domain of human ST2 (Lys19-Ser328, UniProt \#Q01638), a FactorXa cleavage site, and a C-terminal human IgG4 Fc. The ST2-XaFc fusion protein was expressed transiently in Human Embryonic Kidney 293 cells (HEK293) (ATCC, Manassas, VA, USA) and purified by Protein A and preparative size-exclusion chromatography (SEC). The resulting dimeric $\mathrm{Fc}$ fusion protein was treated with Factor Xa enzyme resulting in the cleavage of the Fc. The digested material was incubated with Xarrest Agarose (EMD Millipore, \#69038) to bind and remove Factor Xa enzyme and then passed over a Protein A column again. Unbound protein was collected and polished by preparative SEC. The resulting human ST2 protein was characterized as a monomer by SDS-PAGE and analytical SEC.

Discovery antibodies were expressed in HEK293 or Chinese Hamster Ovary (CHO) cells (Lonza, Morristown, NJ, USA) using mammalian expression vectors encoding the respective light chain and heavy chain. The antibodies were bound to Protein A resin and eluted using low $\mathrm{pH}$ buffer. The eluted antibody was further purified using preparative SEC or cation exchange chromatography (CEX) as a polishing step. Antibody purity was evaluated by SDS-PAGE, analytical SEC-HPLC, and LC/MS analysis. Endotoxin was $<1 \mathrm{EU} / \mathrm{mg}$ as measured by the Endosafe $^{\circledR}$ PTS (Charles River Laboratories, Wilmington, MA, USA). Purified antibodies were buffer exchanged in phosphate-buffered saline (PBS), pH 7.2 and stored at $4^{\circ} \mathrm{C}$. An IgG4 isotype control antibody was generated using a similar method. 


\section{Analytical Assays}

Analytical Heparin Binding Chromatography Assay

Twenty $\mathrm{mg}$ of $\mathrm{IgG}$ samples $(1 \mathrm{mg} / \mathrm{mL})$ in PBS was injected onto a HiTrap Heparin HP $1 \mathrm{~mL}$ column (GE Healthcare, \#17-0406-01). Flow was kept at $1.0 \mathrm{~mL} / \mathrm{min}$ with an initial linear gradient up to $2 \% \mathrm{~B}$ in 3 minutes, then up to $100 \%$ B in an additional 40 minutes. Gradient was kept at $100 \%$ B for an additional 5 minutes to remove any remaining protein. Column was re-equilibrated at $100 \%$ A for 5 minutes prior to the next injection.

\section{Analytical Hydrophobicity Interaction Chromatography Assay}

Twenty $\mathrm{mg}$ IgG samples $(1 \mathrm{mg} / \mathrm{mL})$ were diluted 1:1 with $2 \mathrm{x}$ Buffer A concentrate (2 $\mathrm{M}$ ammonium sulfate, 0.1 $\mathrm{M}$ sodium phosphate at $\mathrm{pH}$ 6.8) to achieve a final ammonium sulfate concentration of $1 \mathrm{M}$ before analysis. A TSKgel butyl-NPR column $(4.6 \mathrm{~mm}$ ID x $10 \mathrm{~cm}, 2.5 \mathrm{um}$, Tosoh \#42168) was used with a linear gradient $(0-100 \%$ B) of mobile phase A (1 M ammonium sulfate, $50 \mathrm{mM}$ sodium phosphate, $\mathrm{pH}$ 6.8) and mobile phase B solution (50 mM sodium phosphate, $\mathrm{pH} 6.8$ ) over $23 \mathrm{~min}$ at a flow rate of $1 \mathrm{~mL} / \mathrm{min}$ with $\mathrm{UV}$ absorbance monitoring at $280 \mathrm{~nm}$.

\section{Antibody Discovery}

To generate antibodies specific to human IL-33, a phage display library displaying fully human Fabs was panned with soluble human IL-33 for three rounds. Positive phage bearing IL-33-binding Fabs were isolated using standard procedures. These were then expressed as a kappa light chain and human IgG4 variant heavy chain (IgG4-PAA) where the modified Fc portion contained an S228P mutation (EU numbering system) in the hinge region to reduce half-antibody formation ${ }^{36}$ and F234A/L235A mutations (EU numbering system) to reduce the effector function of the human IgG4 isotype. ${ }^{37}$ The C-terminal lysine of the IgG4-PAA sequence was removed to reduce chemical heterogeneity during expression. Antibodies were screened for the ability to bind human IL-33, block IL-33/ST2 interaction, and neutralize ST2 signaling. Antibody 23 was identified as a positive hit.

\section{Antibody Optimization}

Antibody 23 was optimized for binding to human IL-33. To accomplish this, the CDRs of the isolated VH and VL were randomized by mutagenesis and resulting antibodies were screened for binding to human IL-33 using a filter lift and confirmed by enzyme linked immunosorbent assay (ELISA). ${ }^{38}$ Affinity enhancing mutations were then combined to yield LSN3330868 which was then optimized using a framework library approach. For the framework library, twelve human VH framework germline genes (1$24,1-46,1-69,2-5,3-15,3-23,3-53,3-72,4-04,4-39$, 5-51, and 6-01) and eight human VL framework genes (A-19, A-26, A-27, B-2, B-3, L-2, L-12, and O-2) containing LSN3380868 CDRs were synthesized, cloned into heavy and light chain human IgG4-PAA expression vectors, expressed in HEK293, and subsequently screened for binding to human IL-33 by ELISA. From this library, three framework variants (LSN3330868, LSN3348360, LSN3348361) were selected and further characterized by transient $\mathrm{CHO}$ expression titer and analytical assays. LSN3348360 (3-53 heavy chain human framework and A27 human light chain framework) was chosen for further development and optimized for binding to cynomolgus monkey IL-33. To accomplish this, the CDRs of the isolated VH and VL of LSN3348360 were randomized by mutagenesis and resulting antibodies screened for binding to human IL-33 and cynomolgus monkey IL-33 by filter lift and ELISA. Affinity enhancing mutations to cynomolgus monkey IL-33 which did not significantly impact affinity to human IL-33 were then combined to yield LSN3358818 which was then further engineered to reduce potential immunogenicity, which resulted in torudokimab (LY3375880). The clinical candidate was expressed in $\mathrm{CHO}$ and purified as described above.

\section{Blocking Assay}

Antibodies to IL-33 were used in a blocking ELISA assay to determine their ability to block human IL-33 (90-270) binding to human ST2. Briefly, an ELISA plate coated with 50ul of goat anti-human IgG1 antibody (Jackson ImmunoResearch Laboratories, \#109-005-098) at 1ug/mL was used to capture 50ul of human ST2-Fc (R\&D Systems, \#523-ST-100) at $1 \mathrm{mg} / \mathrm{mL}$ following incubation for 1 hour at room temperature. Torudokimab and the corresponding isotype control antibody were then titrated and pre-incubated for 1 hour at room temperature with a fixed concentration of biotinylated IL-33 before incubating in the ELISA plate for 20 minutes at room temperature. After washing the plate, bound biotinylated IL-33 was detected using Alkaline phosphatase labelled Neutravidin (ThermoFisher Scientific, \#31002). 


\section{Binding Affinity and Specificity}

The binding kinetics and affinity of torudokimab to human, cynomolgus monkey, mouse, rat, and rabbit IL33 were determined using a surface plasmon resonance (SPR) assay on either a Biacore T100 or T200 instrument primed with HBS-EP+ (10 mM Hepes $\mathrm{pH} 7.4,150 \mathrm{mM}$ $\mathrm{NaCl}, 3 \mathrm{mM}$ EDTA, $0.05 \%$ surfactant P20, GE Healthcare Life Sciences, Marlborough, MA, USA) running buffer and analysis temperature set at $37^{\circ} \mathrm{C}$. A CM4 chip containing immobilized Protein A (generated using standard NHS-EDC amine coupling) on all four flow cells was used to employ a capture method. Antibody samples were prepared at $10 \mu \mathrm{g} / \mathrm{mL}$ by dilution into running buffer. Mouse, rat, and rabbit IL-33 samples were prepared at final concentrations of $1000,500,250,125,63,31,16$, and 0 (blank) $\mathrm{nM}$ by dilution into running buffer. Human and cynomolgus IL-33 samples were prepared at final concentrations of $250,125,63,31,16,8,4,2,1$, and 0 (blank) $\mathrm{nM}$ by dilution into running buffer. A fresh, singleuse aliquot of IL-33 was used for each replicate experiment to prevent multiple freeze-thaw cycles. Data were processed using standard double referencing and fit to a 1:1 binding model using Biacore Evaluation software (version 2.0.1), to determine the association rate (on-rate, $\mathrm{k}_{\mathrm{on}}, \mathrm{M}^{-1} \mathrm{~s}^{-1}$ units) and the dissociation rate (off-rate, $\mathrm{k}_{\mathrm{off}}$, $\mathrm{s}^{-1}$ units). The equilibrium dissociation constant $\left(\mathrm{K}_{\mathrm{D}}\right)$ was calculated from the relationship $K_{D}=k_{\text {off }} / k_{\text {on }}$ and is in molar units. Three experimental replicates (n) were conducted for the binding of torudokimab to human and cynomolgus monkey IL-33. To assess binding affinity to human IL-1 $\alpha$, IL-1 $\beta$ (PeproTech, Inc., Rocky Hill, NJ, USA), IL-18 (MBL International, Woburn, MA, USA),

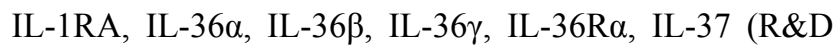
Systems, Minneapolis, MN, USA) torudokimab was tested at concentrations up to $500 \mathrm{nM}$ by using this same basic procedure.

\section{Cell-Based Neutralization Assays Luciferase Reporter Assay}

Human glomerular endothelial cell (GEC) line (Applied Cell Biology Research Institute, Kirkland, WA, USA) transfected with NFkB-Luciferase (NFkB-Luc) (generated inhouse) were routinely cultured in assay medium (EGM ${ }^{\mathrm{TM}}$ BulletKit $^{\mathrm{TM}}$ medium (LONZA, Basel, Switzerland) plus puromycin). On the day prior to the assay, confluent GECNFkB-Luc cells were removed with trypsin, spun down, washed and resuspended in fresh media. The cells were plated in triplicate for biological replicates at 5000 cells in $50 \mu \mathrm{L} /$ well in a white walled collagen I treated plate (BD BioCoat $^{\mathrm{TM}}$, BD Biosciences, NJ, USA), and the plate was incubated overnight. The next day the cells were treated with torudokimab in the presence of $2.5 \mathrm{ng} / \mathrm{mL}$ cleaved mature form IL-33 from different species (in-house). A dose range of torudokimab from 0 to $133.3 \mathrm{nM}$ was evaluated. Human monomeric ST2 (in-house) was used as positive control in the assay and an isotype control antibody (in-house) was used as the negative control. Testing was done in triplicates. The 96-well plates were placed in tissue culture incubator $\left(37^{\circ} \mathrm{C}, 95 \%\right.$ relative humidity, $\left.5 \% \mathrm{CO}_{2}\right)$ for 4 hours. Then, $100 \mu \mathrm{L} /$ well of ONE-Glo ${ }^{\mathrm{TM}}$ Luciferase solution (Promega, Madison, WI, USA) was added to measure luciferase activity. A luminometer (VICTOR, ${ }^{3}$ Perkin Elmer, Waltham, MA, USA) was used to read the plates.

\section{Mast Cell Cytokine Secretion Assay}

Human mast cells were differentiated in culture from human cord blood stem cells (StemCell Technologies, Vancouver, Canada) using StemSpan ${ }^{\mathrm{TM}}$ media (StemCell Technologies, Vancouver, Canada) and human stem cell factor (SCF)/IL-6. ${ }^{39}$ On the day of the assay, mast cells were collected from the flasks, centrifuged at $200 \mathrm{~g}$ for 5 min, and re-suspended in fresh media. The cells were plated in triplicate for biological replicates at 50,000 cells in $50 \mu \mathrm{L} /$ well in 96-well tissue culture plate and treated with $10 \mathrm{ng} / \mathrm{mL}$ cleaved mature form of human IL33 in the presence/absence of different antibodies. A dose range of torudokimab from 0 to $30 \mathrm{nM}$ was evaluated. The assay medium alone was used for "no treatment" control. Human monomeric ST2 was used as positive control in the assay and an isotype control antibody was used as the negative control. Testing was done in triplicate. The 96well plates were placed in tissue culture incubator $\left(37^{\circ} \mathrm{C}\right.$, $95 \%$ relative humidity, $5 \% \mathrm{CO}_{2}$ ) for 16 hours. Supernatant of $100 \mu \mathrm{L} /$ well was collected to measure GM-CSF levels by ELISA (R\&D Systems, Minneapolis, MN, USA) according to manufacturer's instructions.

\section{Ethical Use of Animals}

The use of mice and cynomolgus monkeys followed the ethical guidelines stated in the National Institutes of Health Guide for the Care and Use of Laboratory Animals. Animal study protocols were approved by Lilly Animal Policy and Welfare Committee. 


\section{Pharmacodynamic Assay in Mice}

C57BL/6 mice $(\mathrm{n}=5)$ were injected intraperitoneally with $0.94 \mathrm{mg} / \mathrm{kg}, 0.282 \mathrm{mg} / \mathrm{kg}$ or $0.094 \mathrm{mg} / \mathrm{kg}$ (10-fold, 3-fold or equimolar amounts relative to human IL-33 (95-270), respectively) of torudokimab or with an isotype control antibody at $0.94 \mathrm{mg} / \mathrm{kg}$ (10-fold relative to human IL-33). One day postinjection, mice were challenged by intraperitoneal injection of $0.025 \mathrm{mg} / \mathrm{kg}$ of human IL-33 (95-270). Six hours posthuman IL-33 challenge, mice were sacrificed, and serum was collected. Serum was analyzed for levels of mouse IL-5 using a commercial ELISA (R\&D Systems, Minneapolis, MN, USA) according to the manufacturer's instructions.

\section{Single Dose Pharmacokinetics in Cynomolgus Monkey}

The pharmacokinetics (PK) of torudokimab was characterized in male cynomolgus monkeys following a single intravenous (IV) bolus or subcutaneous (SC) administration of $5 \mathrm{mg} / \mathrm{kg}$ with two monkeys per group. Blood samples were collected from the femoral vein prior to dosing and at $1,6,12$, $24,48,72,96,120,168,240,336,504$, and 672 hours after administration. The blood samples were allowed to clot at ambient temperature prior to centrifugation to obtain serum. Serum concentrations were determined using an IL-33 antigen capture or total human IgG ELISA. The standard curve range was $7.8-500 \mathrm{ng} / \mathrm{mL}$ with an upper limit of quantitation (ULOQ) at $200 \mathrm{ng} / \mathrm{mL}$ and a lower limit of quantitation (LLOQ) at $12.5 \mathrm{ng} / \mathrm{mL}$. PK parameters were determined via non-compartmental analysis using Phoenix ${ }^{\circledR}\left(\mathrm{WinNonlin}^{\mathrm{TM}}\right.$ 6.4, Connect 1.4, Pharsight ${ }^{\circledR}$, Saint Louis, MO, USA).

\section{Results}

\section{Antibody Engineering and Affinity Determination}

The IL-33 Antibody 23 discovered from the phage library had a low affinity $(21.9 \mathrm{nM})$ contained 3-23 (VH) and A27 (VK) germlines and had eight non-germline somatic hypermutations in the framework regions of the VK domain.
Affinity maturation of Antibody 23 to enhance binding to human IL-33 and reverting framework somatic hypermutations resulted in Antibody LSN3330868 which bound human IL-33 with an affinity of $34 \mathrm{pM}$ and cynomolgus monkey IL-33 with an affinity of 9.6 nM. Further, engineering using framework library shuffling resulted in Antibody LSN3348360 containing 3-53 and A27 germlines that bound to human IL-33 with an affinity of $14.5 \mathrm{pM}$ and bound to cynomolgus monkey IL-33 with an affinity of $12.4 \mathrm{nM}$, representing an $\sim 850$-fold difference in species cross-reactivity. The expression of the framework optimized LSN3348360 (3-53/A27) and LSN3348361 (3-53/L12) variants in transient $\mathrm{CHO}$ resulted in higher titers as compared to LSN3330868 (3-23/A27). Analytical hydrophobic interaction chromatography (aHIC) was used to determine the relative hydrophobicity. Analytical heparin-binding chromatography (aHeparin) was used to determine the relative heparin-binding profile. All three framework variants had low hydrophobicity, but LSN3348360 exhibited reduced nonspecific binding to Heparin compared to LSN3330868 and LSN3348316. These data are summarized in Table 1. Based on this profile, LSN3348360 was identified as the lead antibody. LSN3348360 was then optimized for binding to cynomolgus monkey IL-33. This antibody bound to human IL-33 with an affinity of $46 \mathrm{pM}$ and bound to cynomolgus monkey IL-33 with an affinity of $217 \mathrm{pM}$ representing a 5 -fold difference in species cross-reactivity. LSN3358818 was then further engineered to reduce potential immunogenicity, which resulted in the clinical candidate antibody LY3375880 (torudokimab).

To characterize the binding kinetics of torudokimab to different IL-33 species and assess binding to members of the IL-1 family, we used Biacore. Table 2 summarizes the association rate $\left(\mathrm{k}_{\mathrm{on}}\right)$, the dissociation rate $\left(\mathrm{k}_{\mathrm{off}}\right)$, and binding affinity $\left(\mathrm{K}_{\mathrm{D}}\right)$ of the lead antibody (LSN3348360) and torudokimab to various IL-33 ligands. Torudokimab bound to human and cynomolgus monkey IL-33 (95-270) with binding affinities $\left(\mathrm{K}_{\mathrm{D}}\right)$ of $49 \mathrm{pM}$ and $338 \mathrm{pM}$, an improved $\sim 7 \mathrm{X}$ differential compared to LSN3348360, which has

Table I Characterization of Framework Library Antibody Variants. Relative Binding for Each Analytical Assay Was Evaluated as Follows: Low Binding (+), Moderate Binding (++), High Binding (+++)

\begin{tabular}{|l|c|c|c|c|c|}
\hline $\begin{array}{l}\text { Framework } \\
\text { Antibody Variant }\end{array}$ & $\begin{array}{c}\text { Heavy Chain } \\
\text { Framework }\end{array}$ & $\begin{array}{c}\text { Light Chain } \\
\text { Framework }\end{array}$ & $\begin{array}{c}\text { Transient CHO } \\
\text { Titer (mg/L) }\end{array}$ & $\begin{array}{c}\text { aHIC (Relative } \\
\text { Binding) }\end{array}$ & $\begin{array}{c}\text { aHeparin (Relative } \\
\text { Binding) }\end{array}$ \\
\hline LSN3348360 & $3-53$ & A27 & 106 & + & + \\
LSN334836I & $3-53$ & LI2 & 96 & + & +++ \\
LSN3330868 & $3-23$ & A27 & 40 & + \\
\hline
\end{tabular}


Table 2 Binding Kinetics and Affinity of IL-33 Monoclonal Antibodies at $37^{\circ} \mathrm{C}$

\begin{tabular}{|c|c|c|c|c|c|}
\hline \multirow[t]{2}{*}{ Antibody } & \multirow[t]{2}{*}{ Antigen } & $k_{\text {on }}\left(M^{-1} s^{-1}\right)$ & $k_{\text {off }}\left(s^{-1}\right)$ & $K_{D}(p M)$ & \multirow[t]{2}{*}{$\mathbf{N}$} \\
\hline & & Avg $\pm S D$ & Avg士SD & Avg士SD & \\
\hline LSN3348360 & Human IL-33 (95-270) & $1.7 \pm 0.5 \times 10^{6}$ & $2.6 \pm 0.1 \times 10^{-5}$ & $14.5 \pm 1.5$ & 3 \\
\hline LSN3348360 & Cynomolgus IL-33 (95-270) & $1.7 \pm 0.6 \times 10^{6}$ & $1.9 \pm 0.1 \times 10^{-2}$ & $12,400 \pm 4000$ & 3 \\
\hline Torudokimab & Human IL-33 (95-270) & $1.5 \pm 0.1 \times 10^{6}$ & $7.2 \pm 1.7 \times 10^{-5}$ & $49 \pm 14$ & 3 \\
\hline Torudokimab & Cynomolgus IL-33 (95-270) & $1.5 \pm 0.2 \times 10^{6}$ & $51 \pm 2.0 \times 10^{-5}$ & $338 \pm 45$ & 3 \\
\hline Torudokimab & Mouse IL-33 (I02-266) & \multicolumn{3}{|l|}{$\mathrm{K}_{\mathrm{D}}>1000 \mathrm{nM}$} & 1 \\
\hline Torudokimab & Rat IL-33 (109-264) & \multicolumn{3}{|l|}{$\mathrm{K}_{\mathrm{D}}>1000 \mathrm{nM}$} & I \\
\hline Torudokimab & Rabbit IL-33 (I0I-254) & \multicolumn{3}{|l|}{$\mathrm{K}_{\mathrm{D}}>1000 \mathrm{nM}$} & I \\
\hline
\end{tabular}

Note: Error is reported as the standard deviation (SD).

a $\sim 850 \mathrm{X}$ species differential and lacked binding to mouse, rat, and rabbit IL-33 (KD >1000 nM) (Table 2). The individual binding sensorgrams for LSN3348360 and torudokimab to both human and cynomolgus monkey IL-33 (95-270) are shown in Figure 1.

It was confirmed that torudokimab could inhibit the binding of 30ng/mL IL-33 (95-270) to ST2 with an IC50 of $3.7 \mathrm{nM}$ (Figure 2A). The engineering of human and cynomolgus monkey cross-reactivity was needed to enable downstream non-human primate toxicity studies. Torudokimab did not bind to other members of the human IL-1 family at a concentration of $500 \mathrm{nM}$ (IL-1 $\alpha$, IL-1 $\beta$, IL-18, IL-1RA, IL-36 $\alpha$, IL-36 $\beta$, IL-36 $\gamma$, IL-36R $\alpha$ ), while antibodies used as positive controls to each family member were able to bind specifically to each cytokine (data not shown).

\section{Cell-Based IL-33 Neutralization Assays}

A human GEC NFKB-luciferase cell line naturally expresses ST2 and its co-receptor IL1RAP and was used to measure the ability of IL-33 antibodies to inhibit the activation of the NFKB pathway by IL-33. As shown in
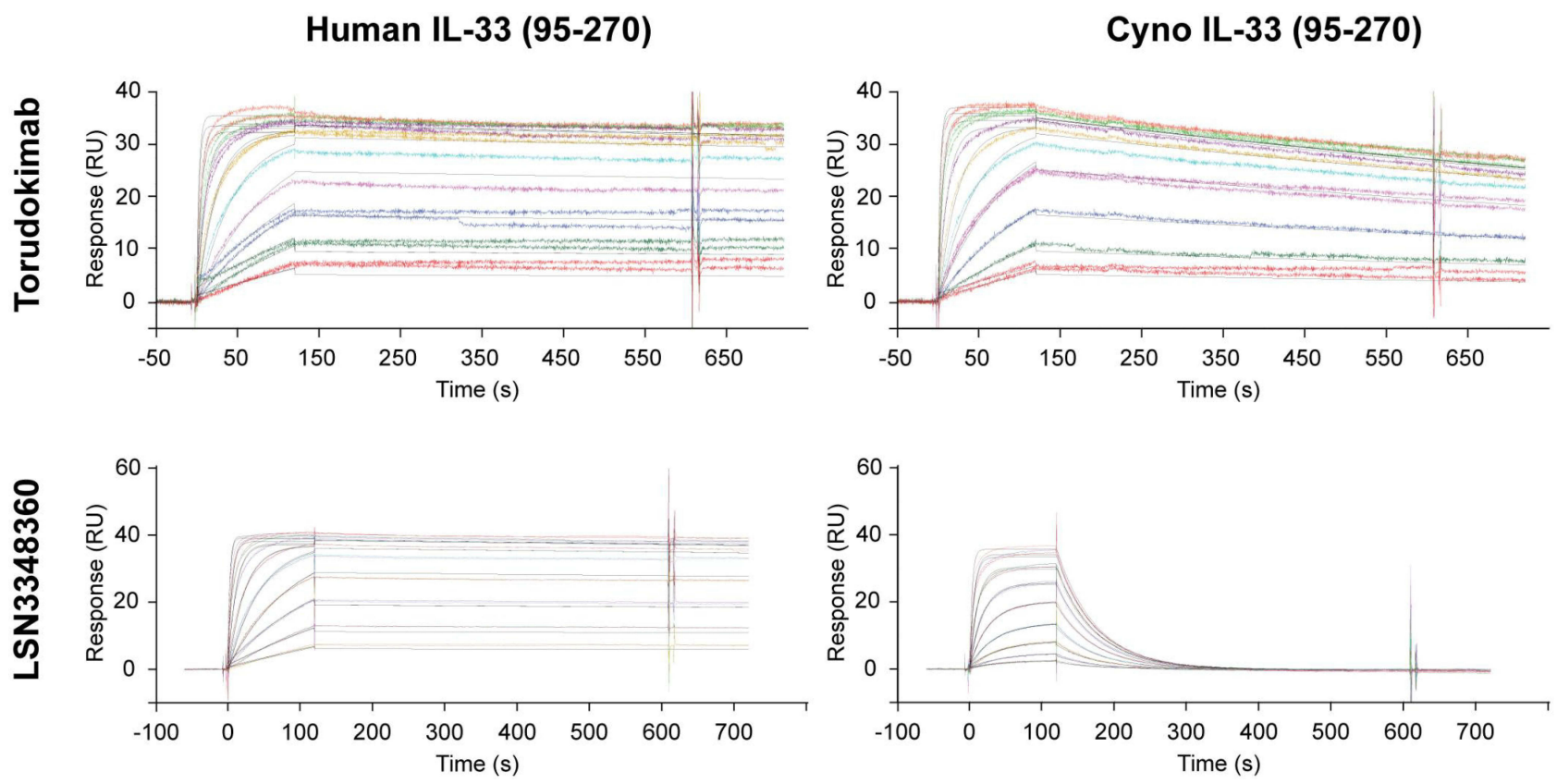

Figure I SPR sensorgrams for the binding kinetics of LSN3348360 and torudokimab to human (95-270) and cynomolgus (95-270) monkey IL-33 at $37^{\circ} \mathrm{C}$. The engineering of LSN3348360 to produce torudokimab resulted in improved binding to cynomolgus monkey IL-33. Antibodies were captured on the surface of a CM4 chip with immobilized Protein A and different concentrations of IL-33 were injected to assess binding kinetics. Double reference subtracted binding sensorgrams are shown. 


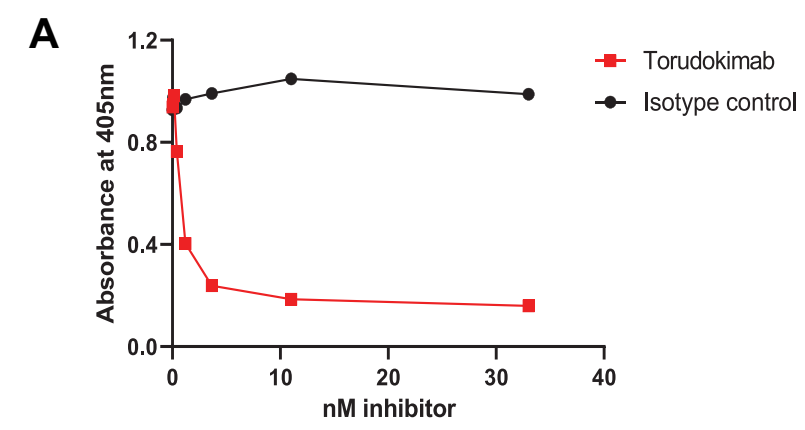

B

Human IL-33

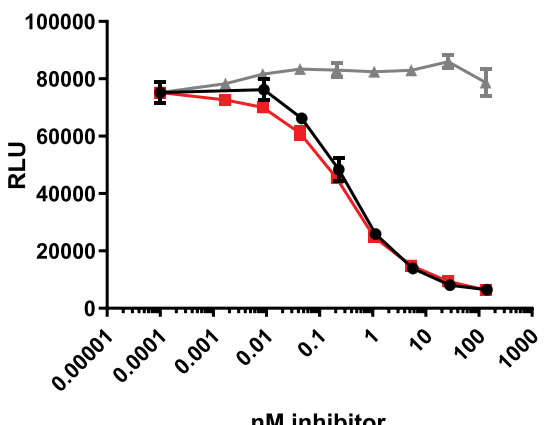

$\mathrm{nM}$ inhibitor
Cyno IL-33

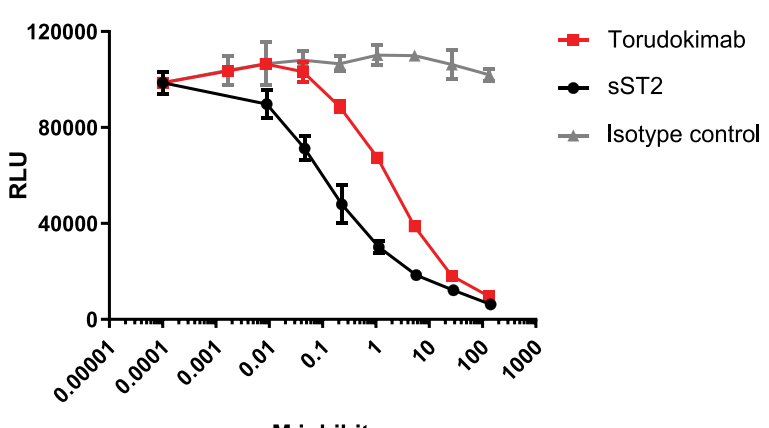

nM inhibitor
Mouse IL-33

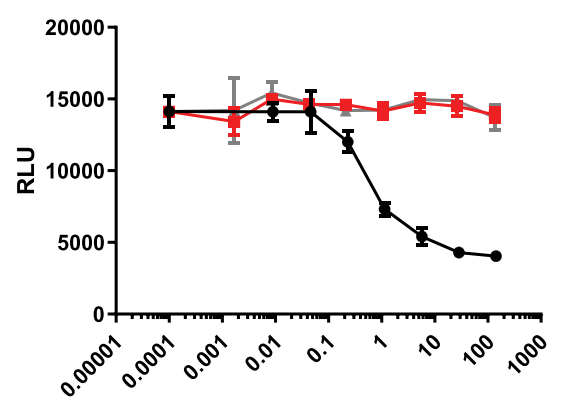

nM inhibitor
Rat IL-33

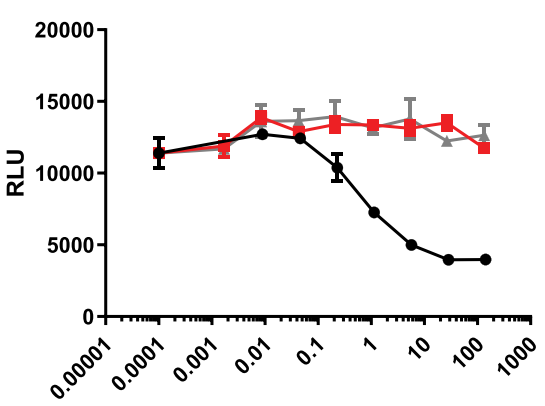

$n M$ inhibitor
Rabbit IL-33

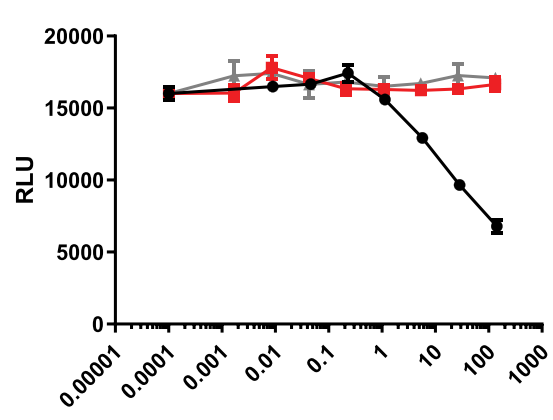

$\mathrm{nM}$ inhibitor

Figure 2 (A) Torudokimab completely inhibited 30ng/mL human IL-33 (95-270) from binding to ST2 in a blocking ELISA assay with an IC 50 of $3.7 \mathrm{nM}$. Results are expressed as $I_{50}$ (half maximal inhibitory concentration) and calculated using a 4-parameter sigmoidal fit of the data (GraphPad, Prism). (B) Torudokimab completely inhibited the cleaved mature form of human- and cynomolgus monkey-, but not mouse-, rat- or rabbit- IL-33 induced NFKB activity in a dose-dependent manner. The GEC-NFkB luciferase cell line was treated in biological triplicates with $2.5 \mathrm{ng} / \mathrm{mL}$ IL-33 (95-270) in the presence of the antibodies for 6 hours before luciferase reading was done. IC50 showed that torudokimab inhibited human IL-33 (95-270) at $0.330 \mathrm{nM}$ and cynomolgus monkey IL-33 (95-270) at I.918 nM. Whereas soluble ST2 (sST2), the positive control, inhibited human IL-33 at $0.426 \mathrm{nM}$ and cynomolgus monkey IL-33 at $0.175 \mathrm{nM}$. Results were calculated using a 4-parameter sigmoidal fit of the data (GraphPad, Prism). Results are representative of three independent experiments.

Figure 2B, torudokimab inhibited human- and cynomolgus monkey-, but not mouse-, rat- or rabbit-IL33-induced $\mathrm{NF} \kappa \mathrm{B}$ activity in a dose-dependent manner. The average (+SD) $\mathrm{IC}_{50}$ (half maximal inhibitory concentration) from three independent experiments run in triplicate showed that torudokimab inhibited human IL-33 (95-270) at $0.330+0.112 \mathrm{nM}$ and cynomolgus monkey IL-33 (95270 ) at $1.918+0.152 \mathrm{nM}$. Whereas soluble ST2 (sST2), the positive control, inhibited human IL-33 at $0.426+$ $0.115 \mathrm{nM}$ and cynomolgus monkey IL-33 at $0.175+$ $0.021 \mathrm{nM}$. The negative control antibody did not inhibit

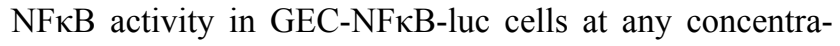
tion tested.

Human mast cells naturally express the ST2 receptor and its co-receptor IL1RAP and their response to human IL-33 results in cytokine secretion. In preliminary studies, IL-33 


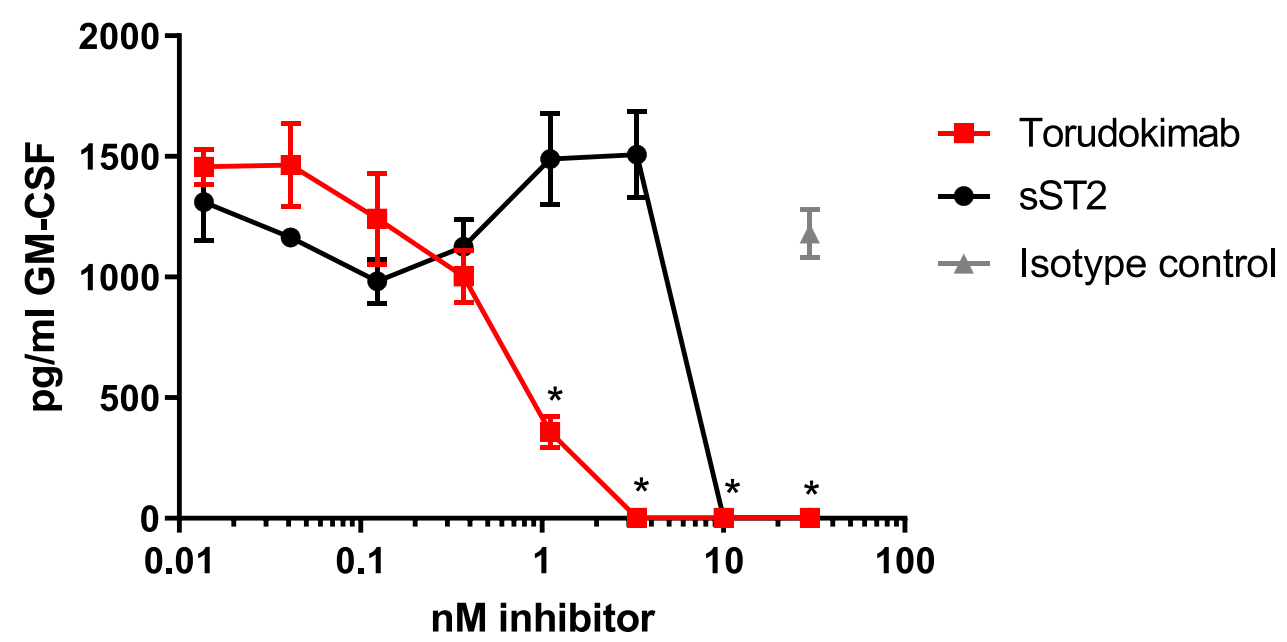

Figure 3 Torudokimab completely inhibits human IL-33 induced GM-CSF secretion from human mast cells in a dose-dependent manner. Mast cells were treated with IOng/ $\mathrm{mL}$ IL-33 (95-270) for 16 hours and the assay was performed in biological triplicates. The inhibition of human IL-33 with torudokimab was lower than the positive control soluble receptor (sST2). Negative isotype control antibody did not inhibit IL-33 induced GM-CSF secretion. ${ }^{*} \mathrm{p}<0.05$ torudokimab compared to isotype control (t-test performed by GraphPad, Prism). Results are representative of two independent experiments.

induced the production of several cytokines including IL-5, IL-13, IL-8, IL-10 and GM-CSF (data not shown). GM-CSF was the mediator selected as an exemplar cytokine to determine whether torudokimab was able to inhibit IL-33activation of primary human cells due to the consistency and magnitude of the GM-CSF response. As shown in Figure 3, torudokimab completely inhibited the cleaved mature form of human IL33-induced GM-CSF secretion from human mast cells in a dose-dependent manner. The isotype control antibody did not inhibit IL-33 induced GM-CSF secretion. Results are representative of two independent experiments.

\section{Pharmacodynamic Assay in Mice}

To determine neutralization of IL-33 in vivo we used a pharmacodynamic model in the mouse. Previous work demonstrated that intraperitoneal injection of human IL-33 into a mouse induced the production of mouse IL-5, which can readily be measured in serum. ${ }^{1}$ IL-5 was selected as the representative cytokine for the pharmacodynamic model due to the reproducibility of the response following a single injection of IL-33. Torudokimab at 3 different doses or an isotype control $\mathrm{Ab}$ was administered 1 day prior to injection of the IL-33 stimulus. Six hours later, mouse serum was collected and analyzed for IL-5 levels. As shown in Figure 4, torudokimab was able to completely inhibit the IL-33-driven increase of mouse IL-5 in a dose dependent manner. The isotype control antibody did not inhibit the human IL-33-induced increase in mouse IL-5. These data demonstrate that torudokimab neutralizes human IL-33 in vivo.

\section{Single-Dose Pharmacokinetics in Monkeys}

Single-dose PK of torudokimab was characterized in male cynomolgus monkeys (Figure 5). Elimination rate was typical of an IgG4 antibody. ${ }^{35}$ The mean clearance of torudokimab, estimated by total IgG ELISA, was approximately $0.21 \mathrm{~mL} / \mathrm{hr} / \mathrm{kg}$ for the IV dose group with complete bioavailability following SC route administration (Table 3). The mean terminal half-life following IV administration was estimated to be approximately 250 to 280 hours (Table 3). PK profiles following SC or IV administration did not suggest an impact of anti-drug antibodies, if present, on torudokimab exposures. Overall, torudokimab exhibited favorable PK properties, supporting monthly dosing in humans.

\section{Discussion}

IL-33 plays many roles in both tissue homeostasis and driving innate and adaptive inflammatory responses in a wide variety of barrier tissue. It is widely known as a driver of allergic responses through the excess activation of mast cells, ${ }^{12}$ basophils, ${ }^{13}$ and ILC2 cells ${ }^{15,16}$ leading to increased cell migration and the production of canonical Th2 cytokines. Mast cells can be used as an example of the strong biological effects of IL-33 due to their high levels of ST2 expression. IL-33 has been shown to induce a larger release of cytokines and chemokines from human mast cells than TSLP. ${ }^{40}$ Additionally, IL-33 can potentiate IgE induced human mast cell degranulation and drive individual mast cells to a higher magnitude of degranulation. ${ }^{41}$ Due to the 


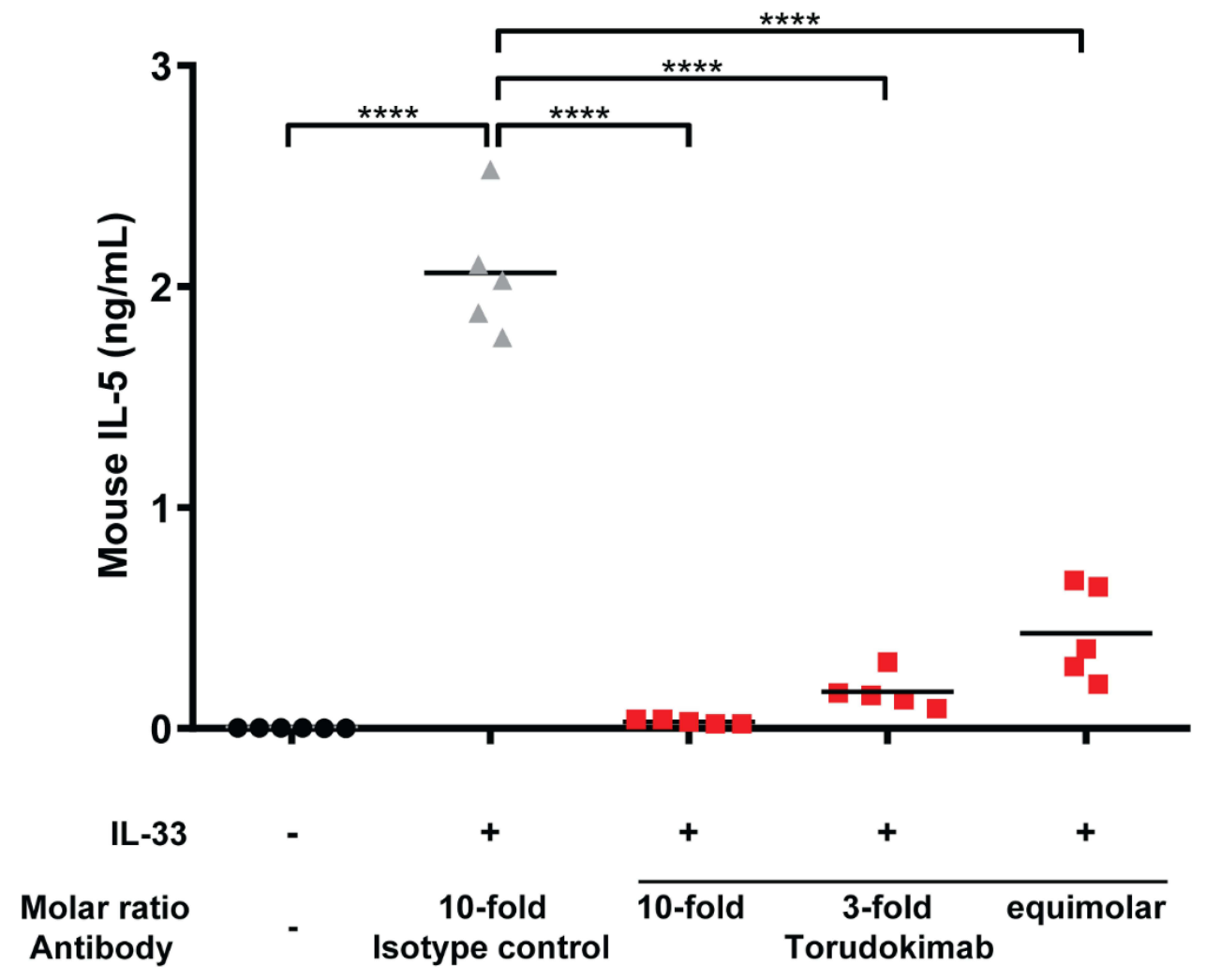

Figure 4 Torudokimab inhibits IL-33-induced production of mouse IL-5 in vivo in a dose dependent manner (individual mouse scatter plot plus mean). C57BL/6 mice ( $\mathrm{n}=5$ ) were injected intraperitoneally with $0.94 \mathrm{mg} / \mathrm{kg}, 0.282 \mathrm{mg} / \mathrm{kg}$ or $0.094 \mathrm{mg} / \mathrm{kg}$ (I0-fold, 3-fold or equimolar amounts relative to human IL-33 respectively) of torudokimab or with an isotype control antibody at $0.94 \mathrm{mg} / \mathrm{kg}$ ( 10 -fold relative to human IL-33). One day post-injection, mice were challenged by intraperitoneal injection of $0.025 \mathrm{mg} / \mathrm{kg}$ of human IL-33. Six hours post-human IL-33 challenge, mice were sacrificed, and serum was collected. The negative isotype control antibody did not inhibit the human IL-33induced production of mouse IL-5. Results are representative of two independent experiments. One-way ANOVA with Dunnett's multiple comparisons test was performed; $* * * * p<0.0001$.

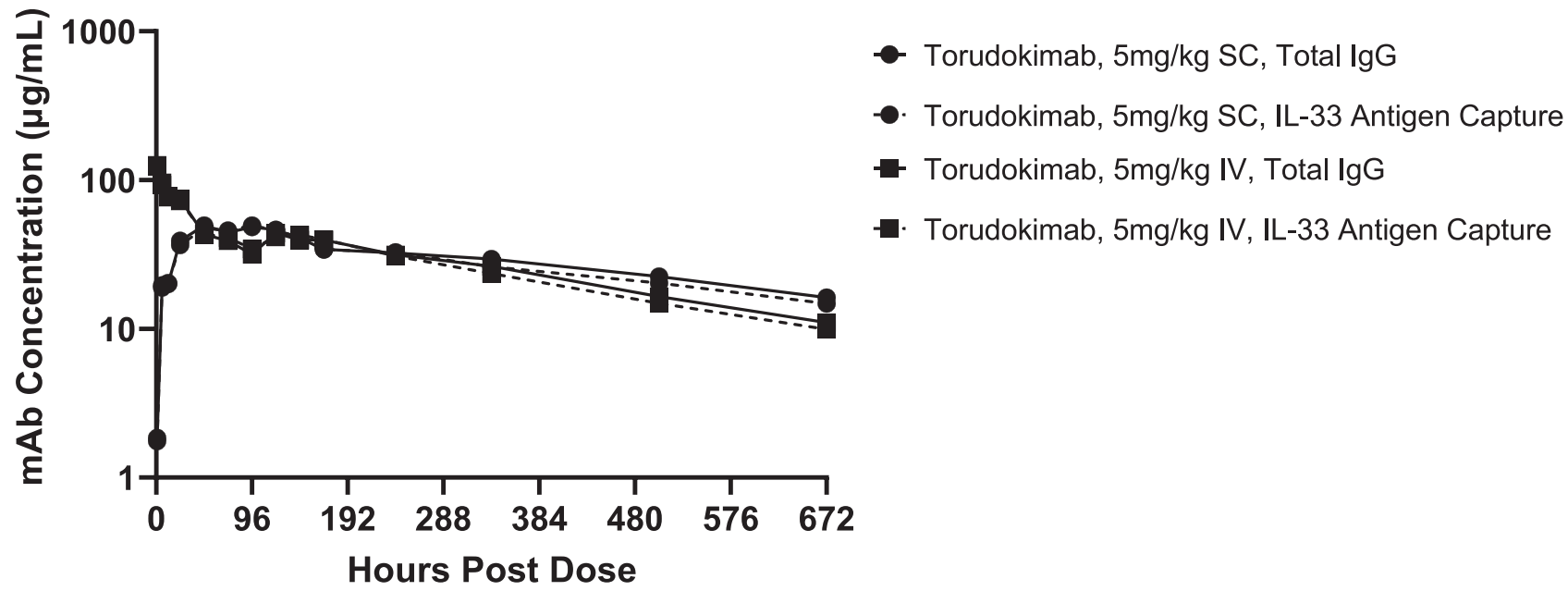

Figure 5 Mean serum concentrations of torudokimab in male cynomolgus monkeys ( $n=2$ monkeys/group) following a single intravenous (IV) or subcutaneous (SC) dose of $5 \mathrm{mg} / \mathrm{kg}$ with concentrations show for both IL-33 antigen capture and total IgG ELISAs.

profound biological effects of IL-33, nature has devised multiple endogenous mechanisms to regulate IL-33 activity including binding to soluble form of ST2 receptor that circulates at relatively high levels, ${ }^{4}$ inactivation by oxidation at cysteine residues, ${ }^{42}$ and protease cleavage and degradation by neutrophil and mast cell enzymes. ${ }^{43}$ These 


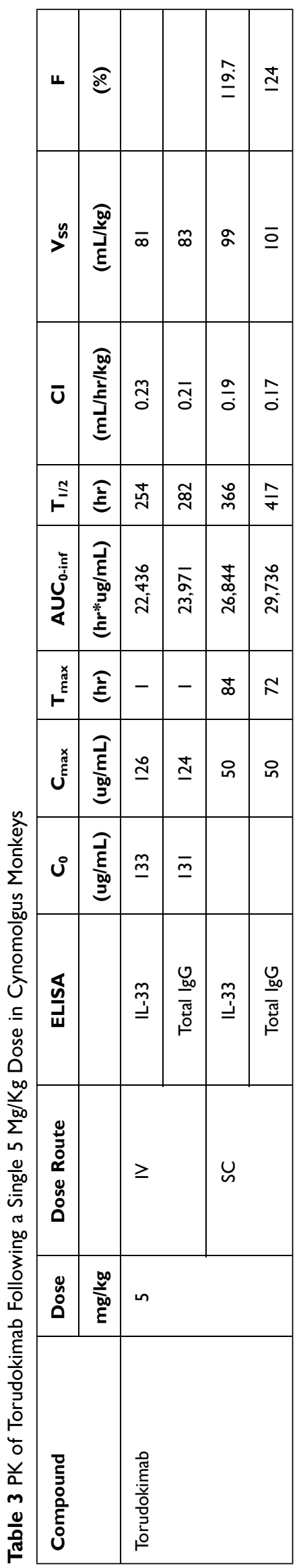

multiple mechanisms to control levels of active IL-33 imply that it is important to regulate IL-33 activity to prevent immune-hyper-reactivity. As such, we hypothesized that additional control over the IL-33/ST2 signaling pathway would be beneficial in some disease states and this idea drove us to develop a high affinity neutralizing IL-33 mAb that completely inhibited the IL-33/ST2 interaction.

Our data demonstrate that we were able to develop a fully human mAb that completely neutralizes human IL-33 activity. The lead molecule bound to human IL-33 with an affinity of $14.5 \mathrm{pM}$, tighter than the $450 \mathrm{pM}$ IL-33:ST2 affinity previously reported in the literature. ${ }^{44}$ However, it had a $12,400 \mathrm{pM}$ affinity to cynomolgus monkey IL-33, representing an $\sim 850$ fold difference in species cross-reactivity (Table 2). This difference was seen despite $94 \%$ sequence identity between human and cynomolgus monkey IL-33. ${ }^{45}$ Additional affinity maturation against the cynomolgus monkey IL-33 along with further engineering to reduce potential immunogenicity, resulted in the molecule chosen for further clinical development, torudokimab. Torudokimab binds to human IL-33 with an affinity of $49 \mathrm{pM}$ and to cynomolgus monkey IL-33 with an affinity of $338 \mathrm{pM}$, representing an $\sim$ 7-fold difference in species cross-reactivity (Table 2). These affinity measurements were performed at $37^{\circ} \mathrm{C}$, to understand physiologically relevant binding; we do not know the temperature used to determine the affinity between human IL-33 and ST2 of $450 \mathrm{pM}$ (ref 42), but even so, torudokimab binds much tighter to IL-33 than IL-33 binds to ST2, making it a highly competitive mAb. Torudokimab does not bind to mouse, rat or rabbit forms of IL-33 nor does it bind to any of the other IL-1 family members (Table 2). Additionally, torudokimab was able to completely inhibit IL-33 interaction with ST2 (Figure 2A), neutralize human IL-33 activity in in vitro cell-based assays as shown by the inhibition in the GEC-NFKB reporter assay and the blockade of GM-CSF secretion from human mast cells (Figure 2B) with a greater potency than the sST2 positive control. This demonstrates that torudokimab is a better competitive agent than SST2, consistent with the higher affinity of torudokimab to IL-33 compared to IL-33 to ST2. In an in vivo mouse model of human IL-33 activity as measured by serum IL-5 levels, torudokimab completely inhibited the IL-5 production (Figure 4). Together, the data demonstrate that torudokimab is a highly potent, selective inhibitor of human IL-33 activity.

There are three major therapeutic strategies for blocking the binding of IL-33 to ST2 - optimized soluble decoy receptors, ST2 neutralizing antibodies or IL-33 neutralizing antibodies. Our team decided against pursuing the soluble decoy 
receptor strategy due to the difficulty in developing a stable molecule with a sufficiently long clinical half-life. ST2 is highly expressed in multiple cell types including both immune cells and stromal cells. ${ }^{46}$ Additionally, soluble ST2 is found in the $\mathrm{ng} / \mathrm{mL}$ range in serum and is often elevated due to disease. ${ }^{47}$ Due to the high amount of target represented by the receptor and soluble forms of ST2, we decided to focus our efforts on developing a neutralizing IL-33 mAb, which is only observed at low levels in circulation. Out of the several ST2 and IL-33 monoclonal antibodies in clinical development, others including Roche and GSK decided to develop ST2 neutralizing monoclonal antibodies, which are currently in clinical trials for atopic dermatitis and respiratory diseases. Several other companies are developing IL-33 monoclonal antibodies including Sanofi with studies in atopic dermatitis and asthma; AstraZeneca in clinical studies of atopic dermatitis, chronic obstructive pulmonary disease (COPD), diabetic kidney disease and COVID-19, and Mitsubishi Tanabe Pharma is pursuing allergic rhinitis and endometrial related pain as indications. While most of these studies are focused on allergic disease, it is interesting to consider other possibilities for IL-33/ ST2 axis inhibitors. Besides driving a type 2 immune response, IL-33 acts on multiple cell types and can induce other cytokines that are associated with autoimmune disease, such as TNFa, IL-1b, IL-6, and GM-CSF along with several chemokines. $^{48}$ Additionally, genetic polymorphism of IL-33 and ST2 have been linked to inflammatory-bowel disease, ${ }^{49}$ COPD ${ }^{50}$ systemic sclerosis, ${ }^{51}$ rheumatoid arthritis ${ }^{52}$ and systemic lupus erythematosus. ${ }^{53,54}$ These associations suggest there could be a therapeutic role for IL-33 inhibition in multiple inflammatory and autoimmune diseases.

\section{Conclusion}

In conclusion, this study described the discovery and preclinical evaluation of torudokimab, a human IgG4PAA mAb with high affinity and specificity for IL-33. Its high binding affinity to IL-33 translates to complete neutralization of IL-33mediated biological activities in vitro and in vivo. Torudokimab has progressed into a clinical study of atopic dermatitis.

\section{Ethics Approval and Informed Consent}

All mice were housed and maintained at Eli Lilly and Company (Indianapolis, IN) in accordance with the research guidelines of the Institutional Animal Care and Use Committee. Cynomolgus monkeys in the sponsor's stock colony maintained at Covance are maintained and monitored for good health in accordance with Covance SOPs and at the discretion of the laboratory animal veterinarian. Prior to assignment to the study, the health of each animal will be assured (where possible) in accordance with Covance SOPs. All procedures with cynomolgus monkey are in compliance with the Animal Welfare Act Regulations (9 CFR 3).

\section{Acknowledgments}

He Wang, Amy Lin and Yuewei Qian for protein generation. Josef Heuer for GEC-NFאB-luc cell-line generation and Veavi Ching-Yun Chang for statistical support. Dinorath Pamela Olvera Ramos and Garreth Lawrence for medical writing and editorial support.

\section{Funding}

Eli Lilly and Company (no grant numbers apply).

\section{Disclosure}

A. J. Okragly, K. B. Corwin, T. Shiyanova, M. Elia, Q. Zhang, D. He, S. B. Dicker, L. Chlewicki, O. Schroeder, S. M. E. Truhlar, J. Davies, C. N. Patel, and R. J. Benschop are employees of Eli Lilly and Company. Ms. Angela J Okragly, Dr. Chetan N Patel, Dr Stephanie ME Truhlar, Dr Julian Davies, and Dr Robert J Benschop have a patent US10501536B2 issued to Eli Lilly and Co. The authors report no other conflicts of interest in this work.

\section{References}

1. Schmitz J, Owyang A, Oldham E, et al. IL-33, an interleukin-1-like cytokine that signals via the IL-1 receptor-related protein ST2 and Induces $\mathrm{T}$ helper type 2-associated cytokines. Immunity. 2005;23 (5):479-490. doi:10.1016/j.immuni.2005.09.015

2. Moussion C, Ortega N, Girard J-P. The IL-1-Like Cytokine IL-33 Is Constitutively Expressed in the Nucleus of Endothelial Cells and Epithelial Cells In Vivo: a Novel 'Alarmin'? PLoS One. 2008;3(10): e3331. doi:10.1371/journal.pone.0003331

3. Liew FY, Pitman NI, McInnes IB. Disease-associated functions of IL-33: the new kid in the IL-1 family. Nat Rev Immunol. 2010;10 (2):103-110. doi:10.1038/nri2692

4. Cayrol C, Girard J-P. Interleukin-33 (IL-33): a nuclear cytokine from the IL-1 family. Immunol Rev. 2018;281(1):154-168. doi:10.1111/imr.12619

5. Carriere V, Roussel L, Ortega N, et al. IL-33, the IL-1-like cytokine ligand for ST2 receptor, is a chromatin-associated nuclear factor in vivo. Proc Natl Acad Sci U S A. 2007;104(1):282-287. doi:10.1073/ pnas.0606854104

6. Roussel L, Erard M, Cayrol C, Girard JP. Molecular mimicry between IL-33 and KSHV for attachment to chromatin through the H2A-H2B acidic pocket. EMBO Rep. 2008;9(10):1006-1012. doi:10.1038/ embor.2008.145

7. Lefrancais E, Roga S, Gautier V, et al. IL-33 is processed into mature bioactive forms by neutrophil elastase and cathepsin G. Proc Natl Acad Sci U S A. 2012;109(5):1673-1678. doi:10.1073/pnas.1115884109 
8. Lefrancais E, Duval A, Mirey E, et al. Central domain of IL-33 is cleaved by mast cell proteases for potent activation of group-2 innate lymphoid cells. Proc Natl Acad Sci U S A. 2014;111 (43):15502-15507. doi:10.1073/pnas.1410700111

9. Chackerian AA, Oldham ER, Murphy EE, Schmitz J, Pflanz S, Kastelein RA. IL-1 receptor accessory protein and ST2 comprise the IL-33 receptor complex. J Immunol. 2007;179(4):2551-2555. doi:10.4049/jimmunol.179.4.2551

10. Palmer G, Gabay C. Interleukin-33 biology with potential insights into human diseases. Nat Rev Rheumatol. 2011;7(6):321-329. doi:10.1038/nrrheum.2011.53

11. Yang Q, Li G, Zhu Y, et al. IL-33 synergizes with TCR and IL-12 signaling to promote the effector function of CD8+ T cells. Eur J Immunol. 2011;41(11):3351-3360. doi:10.1002/eji.201141629

12. Suzukawa M, Iikura M, Koketsu R, et al. An IL-1 cytokine member, IL-33, induces human basophil activation via Its ST2 Receptor. J Immunol. 2008;181(9):5981-5989. doi:10.4049/jimmunol.181.9.5981

13. Pushparaj PN, Tay HK, H'ng SC, et al. The cytokine interleukin-33 mediates anaphylactic shock. Proc Nat Acad Sci. 2009;106 (24):9773-9778. doi:10.1073/pnas.0901206106

14. Stolarski B, Kurowska-Stolarska M, Kewin P, Xu D, Liew FY. IL-33 exacerbates eosinophil-mediated airway inflammation. $J$ Immunol. 2010;185(6):3472-3480. doi:10.4049/jimmunol.1000730

15. Koyasu S, Moro K. Innate Th2-type immune responses and the natural helper cell, a newly identified lymphocyte population. Curr Opin Allergy Clin Immunol. 2011;11(2):109-114. doi:10.1097/ ACI.0b013e 3283448808

16. Chang YJ, Kim HY, Albacker LA, et al. Innate lymphoid cells mediate influenza-induced airway hyper-reactivity independently of adaptive immunity. Nat Immunol. 2011;12(7):631-638. doi:10.1038/ni.2045

17. Rank MA, Kobayashi T, Kozaki H, Bartemes KR, Squillace DL, Kita H. IL-33-activated dendritic cells induce an atypical TH2-type response. $J$ Allergy Clin Immunol. 2009;123(5):1047-1054. doi:10.1016/j.jaci.2009.02.026

18. Drake LY, Prakash YS. Contributions of IL-33 in non-hematopoietic lung cells to obstructive lung disease. Front Immunol. 2020;2:11.

19. Hsu CL, Neilsen CV, Bryce PJ. IL-33 is produced by mast cells and regulates IgE-dependent inflammation. PLoS One. 2010;5(8):e11944. doi:10.1371/journal.pone.0011944

20. Kondo Y, Yoshimoto T, Yasuda K, et al. Administration of IL-33 induces airway hyperresponsiveness and goblet cell hyperplasia in the lungs in the absence of adaptive immune system. Int Immunol. 2008;20(6):791-800. doi:10.1093/intimm/dxn037

21. Izuhara $\mathrm{K}$, Ohta $\mathrm{S}$, Shiraishi $\mathrm{H}$, et al. The mechanism of mucus production in bronchial asthma. Curr Med Chem. 2009;16 (22):2867-2875. doi:10.2174/092986709788803196

22. Boguniewicz M, Leung DYM. Atopic dermatitis: a disease of altered skin barrier and immune dysregulation. Immunol Rev. 2011;242 (1):233-246. doi:10.1111/j.1600-065X.2011.01027.x

23. Imai Y. Interleukin-33 in atopic dermatitis. J Dermatol Sci. 2019;96 (1):2-7. doi:10.1016/j.jdermsci.2019.08.006

24. Savenije OE, Mahachie John JM, Granell R, et al. Association of IL33-IL-1 receptor-like 1 (IL1RL1) pathway polymorphisms with wheezing phenotypes and asthma in childhood. J Allergy Clin Immunol. 2014;134(1):170-177.

25. Moffatt MF, Gut IG, Demenais F, et al. A large-scale, consortium-based genomewide association study of asthma. $N$ Eng J Med. 2010;363(13):1211-1221. doi:10.1056/NEJMoa0906312

26. Ober C, Nicolae DL. Meta-analysis of genome-wide association studies of asthma in ethnically diverse North American populations. Nat Genet. 2011;43(9):887-892. doi:10.1038/ng.888

27. Tamari M, Hirota T. Genome-wide association studies of atopic dermatitis. J Dermatol. 2014;41(3):213-220. doi:10.1111/1346-8138.12321
28. Li J, Zhang Y, Zhang L. Discovering susceptibility genes for allergic rhinitis and allergy using a genome-wide association study strategy. Curr Opin Allergy Clin Immunol. 2015;15(1):33-40. doi:10.1097/ ACI.0000000000000124

29. Nieuwenhuis MA, Siedlinski M, Van Den Berge M, et al. Combining genomewide association study and lung eQTL analysis provides evidence for novel genes associated with asthma. Allergy. 2016;71 (12):1712-1720. doi:10.1111/all.12990

30. Portelli MA, Dijk FN, Ketelaar ME, et al. Phenotypic and functional translation of IL1RL1 locus polymorphisms in lung tissue and asthmatic airway epithelium. JCI Insight. 2020;5(8). doi:10.1172/jci. insight. 132446

31. Oboki K, Ohno T, Kajiwara N, et al. IL-33 is a crucial amplifier of innate rather than acquired immunity. Proc Nat Acad Sci. 2010;107 (43):18581-18586. doi:10.1073/pnas.1003059107

32. Komai-Koma M, Xu D, Li Y, McKenzie ANJ, McInnes IB, Liew FY. IL-33 is a chemoattractant for human Th2 cells. Eur J Immunol. 2007;37(10):2779-2786. doi:10.1002/eji.200737547

33. Li Y, Chen S, Chi Y, et al. Kinetics of the accumulation of group 2 innate lymphoid cells in IL-33-induced and IL-25-induced murine models of asthma: a potential role for the chemokine CXCL16. Cell Mol Immunol. 2019;16(1):75-86. doi:10.1038/s41423-018-0182-0

34. Imai Y, Yasuda K, Sakaguchi Y, et al. Skin-specific expression of IL-33 activates group 2 innate lymphoid cells and elicits atopic dermatitis-like inflammation in mice. Proc Natl Acad Sci U S A. 2013;110(34):13921-13926. doi:10.1073/pnas.1307321110

35. Liu B, Tai Y, Achanta S, et al. IL-33/ST2 signaling excites sensory neurons and mediates itch response in a mouse model of poison ivy contact allergy. Proc Nat Acad Sci. 2016;113(47):E7572-E7579. doi:10.1073/pnas.1606608113

36. Angal S, King DJ, Bodmer MW, et al. A single amino acid substitution abolishes the heterogeneity of chimeric mouse/human (IgG4) antibody. Mol Immunol. 1993;30(1):105-108. doi:10.1016/01615890(93)90432-B

37. Xu D, Alegre ML, Varga SS, et al. In vitro characterization of five humanized OKT3 effector function variant antibodies. Cell Immunol. 2000;200(1):16-26. doi:10.1006/cimm.2000.1617

38. Wu H, Pfarr DS, Tang Y, et al. Ultra-potent antibodies against respiratory syncytial virus: effects of binding kinetics and binding valence on viral neutralization. J Mol Biol. 2005;350(1):126-144. doi:10.1016/j.jmb.2005.04.049

39. Okragly AJ, Morin SM, Derosa D, et al. Human mast cells release the migraine-inducing factor pituitary adenylate cyclase-activating polypeptide (PACAP). Cephalalgia. 2018;38(9):1564-1574. doi:10.1177/ 0333102417740563

40. Allakhverdi Z, Smith D, Comeau M, Delespesse G. Cutting Edge: the ST2 Ligand IL-33 Potently activates and drives maturation of human mast cells. J Immunol. 2007;179:2051-2054. doi:10.4049/ jimmunol.179.4.2051

41. Joulia R, L'Faqihi FE, Valitutti S, Espinosa E. IL-33 fine tunes mast cell degranulation and chemokine production at the single-cell level. J Allergy Clin Immunol. 2017;140(2):497-509.e410. doi:10.1016/j. jaci.2016.09.049

42. Cohen ES, Scott IC, Majithiya JB, et al. Oxidation of the alarmin IL-33 regulates ST2-dependent inflammation. $J$ Allergy Clin Immunol. 2015;6:8327.

43. Morita H, Nakae S, Saito H, Matsumoto K. IL-33 in clinical practice: size matters? J Allergy Clin Immunol. 2017;140(2):381-383. doi:10.1016/j.jaci.2017.03.042

44. Lingel A, Weiss TM, Niebuhr M, et al. Structure of IL-33 and its interaction with the ST2 and IL-1RAcP receptors-insight into heterotrimeric IL-1 signaling complexes. Structure. 2009;17 (10):1398-1410. doi:10.1016/j.str.2009.08.009 
45. Consortium TU. UniProt: a hub for protein information. Nucleic Acids Res. 2014;43(D1):D204-D212.

46. Liew FY, Pitman NI, McInnes IB. Disease-associated functions of IL-33: the new kid in the IL-1 family. Nat Rev Immunol. 2010;10 (2):103-110.

47. Mueller T, Dieplinger B. The Presage ST2 Assay: analytical considerations and clinical applications for a high-sensitivity assay for measurement of soluble ST2. Expert Rev Mol Diagn. 2013;13 (1):13-30. doi:10.1586/erm.12.128

48. Schwartz C, O'Grady K, Lavelle EC, Fallon PG. Interleukin 33: an innate alarm for adaptive responses beyond $\mathrm{Th} 2$ immunity-emerging roles in obesity, intestinal inflammation, and cancer. Eur J Immunol. 2016;46(5):1091-1100. doi:10.1002/eji.201545780

49. Latiano A, Palmieri O, Pastorelli L, et al. Associations between genetic polymorphisms in IL-33, IL1R1 and risk for inflammatory bowel disease. PLoS One. 2013;8(4):e62144. doi:10.1371/journal. pone. 0062144
50. Sun BB, Ma LJ, Qi Y, Zhang GJ. Correlation of IL-33 gene polymorphism with chronic obstructive pulmonary disease. Eur Rev Med Pharmacol Sci. 2019;23(14):6277-6282.

51. Koca SS, Pehlivan Y, Kara M, et al. The IL-33 gene is related to increased susceptibility to systemic sclerosis. Rheumatol Int. 2016;36 (4):579-584. doi:10.1007/s00296-015-3417-8

52. Li C, Mu R, Guo J, et al. Genetic variant in IL33 is associated with susceptibility to rheumatoid arthritis. Arthritis Res Ther. 2014;16(2): R105. doi:10.1186/ar4554

53. Guo J, Xiang Y, Peng Y-F, Huang H-T, Lan Y, Wei Y-S. The association of novel IL-33 polymorphisms with sIL-33 and risk of systemic lupus erythematosus. Mol Immunol. 2016;77:1-7. doi:10.1016/j.molimm.2016.07.001

54. Xu W, Liu Y, Ye D. Association between IL-33 Gene Polymorphisms (rs1929992, rs7044343) and Systemic Lupus Erythematosus in a Chinese Han Population. Immunol Invest. 2016;45(7):575-583. doi:10.1080/08820139.2016.1193868
Journal of Inflammation Research

\section{Publish your work in this journal}

The Journal of Inflammation Research is an international, peerreviewed open-access journal that welcomes laboratory and clinical findings on the molecular basis, cell biology and pharmacology of inflammation including original research, reviews, symposium reports, hypothesis formation and commentaries on: acute/chronic inflammation; mediators of inflammation; cellular processes; molecular

\section{Dovepress}

mechanisms; pharmacology and novel anti-inflammatory drugs; clinical conditions involving inflammation. The manuscript management system is completely online and includes a very quick and fair peerreview system. Visit http://www.dovepress.com/testimonials.php to read real quotes from published authors. 